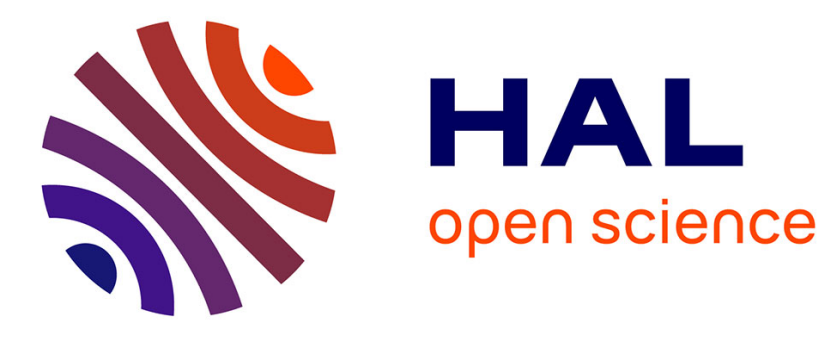

\title{
Racemization and transesterification of alkyl hydrogeno-phenylphosphinates
}

Guilhem Javierre, Rémy Fortrie, Marion Jean, Delphine Moraleda, Jean-Valère Naubron, Frédéric Fotiadu

\section{- To cite this version:}

Guilhem Javierre, Rémy Fortrie, Marion Jean, Delphine Moraleda, Jean-Valère Naubron, et al.. Racemization and transesterification of alkyl hydrogeno-phenylphosphinates. Journal of Molecular Modeling, 2017, 23 (5), pp.168. 10.1007/s00894-017-3343-7 . hal-01683223

\section{HAL Id: hal-01683223 https://hal.science/hal-01683223}

Submitted on 16 Apr 2018

HAL is a multi-disciplinary open access archive for the deposit and dissemination of scientific research documents, whether they are published or not. The documents may come from teaching and research institutions in France or abroad, or from public or private research centers.
L'archive ouverte pluridisciplinaire HAL, est destinée au dépôt et à la diffusion de documents scientifiques de niveau recherche, publiés ou non, émanant des établissements d'enseignement et de recherche français ou étrangers, des laboratoires publics ou privés. 


\title{
Racemization and transesterification of alkyl hydrogeno-phenylphosphinates
}

\author{
Guilhem Javierre $^{1} \cdot$ Rémy Fortrie $^{1}$ (D) Marion Jean $^{1} \cdot$ Delphine Moraleda $^{1}$. \\ Jean-Valère Naubron ${ }^{1} \cdot$ Frédéric Fotiadu $^{1}$
}

\begin{abstract}
In this article, we explore, both theoretically and experimentally, the general reactivity of alkyl hydrogenophenylphosphinates with alcohols. We show that alcohol molecules act exclusively as nucleophilic species, and add to alkyl hydrogeno-phenylphosphinates, leading to pentacoordinated intermediates. These intermediates are shown to subsequently competitively undergo alcohol eliminations and/or Berry pseudorotations. This offers several possible routes for racemizations and/or alcohol exchange reactions. Transition standard Gibbs free energies predicted from DFT calculations for the overall alcohol exchange mechanism are shown to be compatible with those experimentally measured in case ethanol reacts with ethyl hydrogeno-phenylphosphinate $\left(134.5 \sim 136.0 \mathrm{~kJ} \mathrm{~mol}^{-1}\right.$ at $\left.78^{\circ} \mathrm{C}\right)$.
\end{abstract}

\section{Introduction}

Within the framework of constantly improving sustainable chemical processes, asymmetric catalysis plays a key role. Indeed, making synthesis stereoselective significantly contributes to a drastic reduction of waste and energy consumption [1]. This is especially true for pharmaceutical drugs, where stereochemistry must be strictly tuned [2-6].

Since 1968, chiral phosphorus containing molecules have successfully been used as ligands within several asymmetric catalytic processes, which lead to significant industrial breakthroughs $[7,8]$. P-stereogenic ligands, in particular, have shown to be efficient [9-11] and, among them, monodentate P-stereogenic secondary phosphine oxides are thought to be very promising [12-15].

During the past decades, our group has significantly contributed to the making of such ligands. It developed, in particular, an efficient method for preparing P-stereogenic secondary phosphine oxides. It consists in substituting the alkoxy group of a P-stereogenic alkyl hydrogeno-phenylphosphinate with an alkyl anion (Fig. 1) [16, 17]. In doing so, an interesting and questioning observation has been made: the stereoselectivity of the reaction significantly depends on the structure of the alkoxy leaving group. For example, in almost identical experimental conditions, the enantiomeric excess decreases by $13 \%$ for menthyl hydrogeno-phenylphosphinate, whereas it remains constant for adamantyl hydrogenophenylphosphinate (Fig. 1). To our knowledge, however, in this case, there is no obvious reason why such a small change of the structure of the leaving group should result in such a difference of stereoselectivity.

In this article, we would like to bring elements that will help drawing explanations for this difference. More precisely, we here explore, both theoretically and experimentally, the general reactivity of an alkyl hydrogeno-phenylphosphinate 


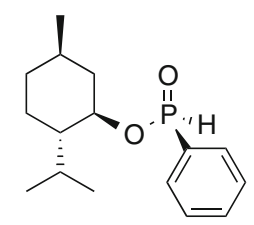

$\left(R_{p}\right)$

de $=99 \%$

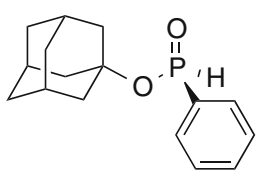

$\left(R_{p}\right)$

ee $=99 \%$
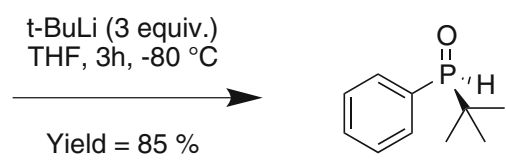

$\left(S_{p}\right)$

ee $=86 \%$
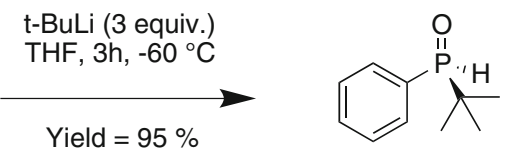

$\left(S_{p}\right)$

ee $=99 \%$
Fig. 1 Substitutions of alkoxy groups on P-stereogenic alkyl hydrogenophenylphosphinates in similar experimental conditions using tert-butyl as a nucleophilic species. Leaving alkoxy groups are (-)-menthoxide (top), and 1-adamantoxide (bottom)

with an alcohol molecule. Traces of alcohol might indeed be contained at some points within the reactive mixture. Practically, such traces could be brought jointly with the reactant, or could be generated in situ at the very beginning of the reaction. Either such situation systematically occurs within the conditions of every experiment is controversy, and this question is out of the scope of this article. We here chose to focus only on what would happen, or not, if such a situation would take place.

\section{Methods}

We here aim to deal only with the intrinsic reactivity of the compounds of interest. As a consequence, we have chosen to keep only the relevant chemical functions for these compounds, and avoid subsidiary substituent effects. Therefore, we chose methyl hydrogeno-phenylphosphinate 1 (MeHP), and methanol 2 as reactants (Fig. 2). Any further simplification, like replacing the phenyl group for example, would lead to questionable results. This would indeed significantly change the electronic properties of the phosphine oxides substituents, which Bickelhaupt has shown to strongly influence the nucleophilic substitution mechanism itself $[18,19]$.
From a reactivity point of view, methanol can act as a base, an acid or a nucleophile. Kinetically, acido-basic reactions certainly take place, resulting in proton exchanges between molecules. Methanol can indeed protonate the oxygen atom of the MeHP molecule that is doubly bonded to the phosphorus atom, leading to 4 and 5 (Fig. 2) or, on the contrary, deprotonate the MeHP molecule by removing the proton that is directly bonded to the phosphorus atom, leading to $\mathbf{6}$ and 7 (Fig. 2). Additionally, MeHP molecules are known for their prototropic equilibrium, where the hydrogen atom that is directly bonded to the phosphorus atom moves to the doubly bonded oxygen atom, leading to the corresponding phosphonous acid 3 [20, 21] (Fig. 2).

This prototropic equilibrium has already been shown to be strongly displaced toward the phosphine oxide form [21-24]. As shown within the next section, this fact is confirmed by our calculations. The same calculations also lead to the conclusion that all acidobasic equilibria are here strongly displaced toward the neutral species. In other words, in a solution that contains only methanol and MeHP molecules in an aprotic solvent, both molecules exclusively adobt their neutral forms, and proton exchange reactions preserve the configuration of the stereogenic phosphorus center. Hereafter, we consequently focus exclusively on the nucleophilic reactivity of methanol on the phosphorus atom of MeHP.

Geometrically, all four substituents of the phosphorus atom in the MeHP molecule are located at the vertices of a tetrahedral structure (Fig. 3). Vertices, faces, and edges of this tetrahedron are hereafter numbered using the Cahn-Ingold-Prelog (CIP) rules as described in Fig. 3.

During the nucleophilic attack of methanol on MeHP, the oxygen atom of methanol approaches the phosphorus center in the middle of a face of the tetrahedron (F1 to F4). At the same time, the alcoholic hydrogen atom of methanol is placed either in the neighborhood of a vertex (V1 to V4) or in the middle of an edge (E12 to E34) as represented in Fig. 4. Six possible hydrogen positions are consequently associated with each face of the tetrahedron, which globally makes 24 possible attacks (Fig. 5). These last are named using the face index followed by the position of the hydrogen atom. F2-V1, for example, corresponds to the approach of the methanol opposite to the methoxy substituent (face 2), with the hydrogen
Fig. 2 Conceivable proton exchange reactions between methyl hydrogenophenylphosphinate (1) and methanol (2)

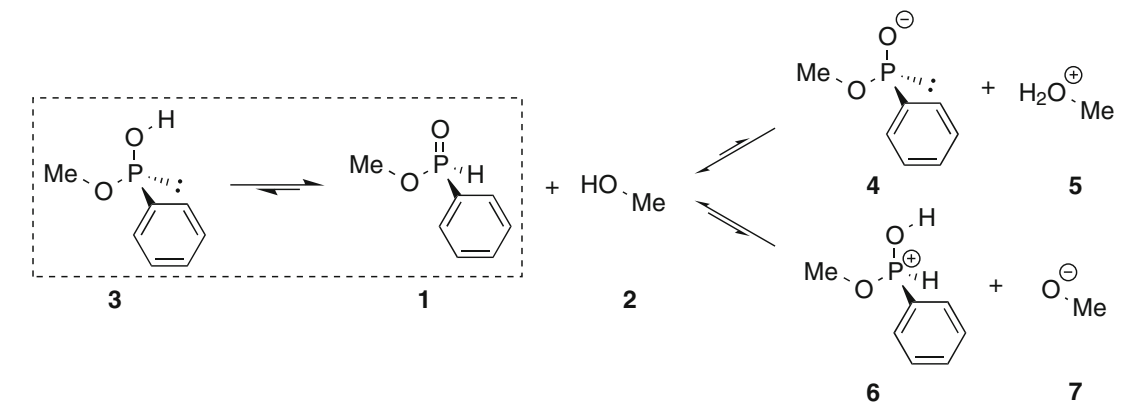



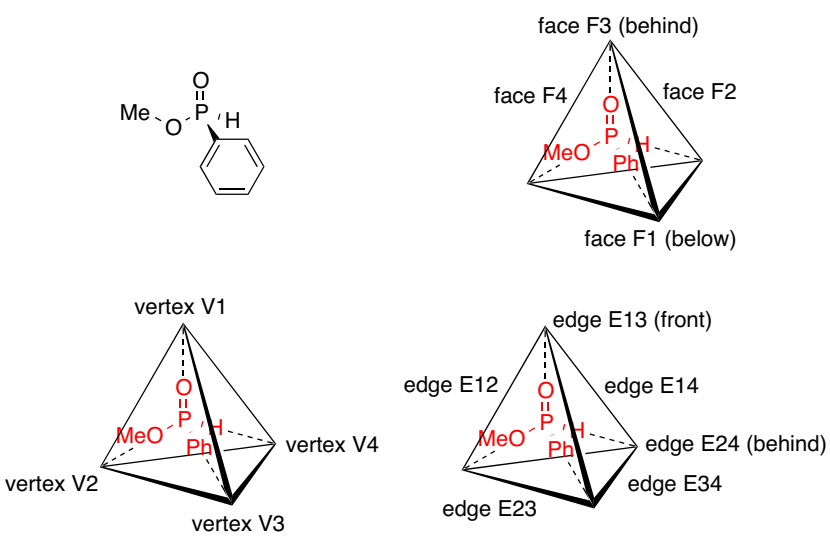

Fig. 3 Tetrahedral geometry of the methyl hydrogeno-phenylphosphinate molecule around its $\mathrm{P}$ stereogenic center. Vertices are numbered using the Cahn-Ingold-Prelog rules applied to the corresponding substituents. In the present case, substituents have the following order: oxygen, methoxy, phenyl, hydrogen. Faces are numbered using the same rules, but applied to the opposite substituent of each face. Finally, edges are numbered using the neighboring vertices

atom located in the vicinity of the doubly bonded oxygen atom (vertex 1).

Note that freezing the position of the hydroxyl group of methanol does normally not determine the whole position of the alcohol with respect to the phosphinate molecule. The methyl group of methanol should indeed still exhibit several degrees of freedom. However, at the PM6 level (vide infra for modeling details), this methyl group exhibits, for all 24 attacks, a single stable position. The position of the hydroxyl group of methanol during the nucleophilic attack consequently practically fully determines the position of the whole methanol molecule with respect to the phosphinate molecule.

Every one of these 24 possible nucleophilic attacks is then investigated as follows. A full chain modeling, which consists in seeking transition structures by optimizing several points of a rope tightened between reactants and products, is performed using the PM6 semi-empirical method (Ampac [25]) and the resulting reactive pathway is subsequently modeled using density functional theory (Gaussian09 [26]). Reaction intermediates and transition structures are all vibrationally characterized and internal released channel (IRC) calculations are performed on transition structures in order to locate the intermediates that are directly related to them.

Technically speaking, since we are here dealing with non-exotic organic molecules, we use M06-2X as a functional

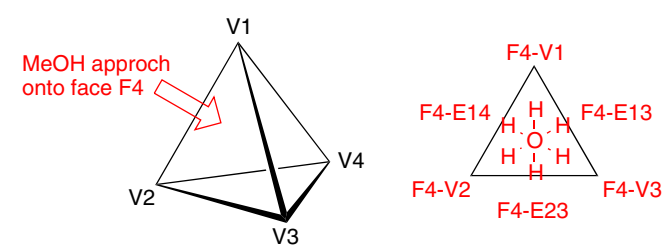

Fig. 4 Generic description of the 24 possible attacks of methanol when it reacts nucleophilically with methyl hydrogeno-phenylphosphinate
[27] and 6-31++G** as a basis set, and we added SMD as an implicit solvent model for all calculations (THF solvent with default thresholds) [28].

Reaction standard Gibbs free energies $\left(\Delta_{\mathrm{r}} \mathrm{G}^{\circ}\right)$ and transition standard Gibbs free energies $\left(\Delta_{\mathrm{r}} \mathrm{G}^{\circ}\right)$ are calculated within the thermodynamic framework of the perfect solution at standard solute concentrations $\left(c^{\circ}=1 \mathrm{~mol} . L^{-1}\right)$. Translational, rotational, and vibrational partition functions are calculated for molecules that are free to move. Rotational partition functions are estimated within the framework of the rigid rotator approximation. Vibrational partition functions are estimated within the framework of the harmonic approximation. All Cartesian molecular structures and relevant structural information are provided within the supporting material.

Finally, our most significant results are modeled again with a different basis set, 6-311++G**, using the now classical B3LYP functional and the CPCM implicit solvent model (THF solvent with default thresholds) [29, 30]. These additional DFT modelings aim to test the methodology independency of the chemical conclusions that we draw at the end of this article.

\section{Prototropic equilibrium}

As mentioned within a previous paragraph, the prototropic equilibrium involving MeHP $\mathbf{1}$ and its phosphonous acidic equivalent $\mathbf{3}$ has already been shown to be, in slightly different cases, strongly displaced toward the phosphine oxide form [21-24]. Our calculations lead exactly to the same result. The reaction standard Gibbs free energy that we obtain for this equilibrium $(\mathbf{3}=\mathbf{1})$ is indeed $-14 \mathrm{~kJ} \mathrm{~mol}^{-1}$ at $25{ }^{\circ} \mathrm{C}$ $\left(-17 \mathrm{~kJ} \mathrm{~mol}^{-1}\right.$ at $\left.50{ }^{\circ} \mathrm{C}\right)$. We can consequently assume that the phosphonous acid $\mathbf{3}$ is absent in the reactive mixture.

\section{Acidobasic reactions}

We now determine which neutral, protonated or deprotonated forms of methanol and MeHP coexist at the equilibrium.

Unfortunately, we were unable to find experimental $\mathrm{pKa}$ values in THF for the compounds we are interested in here. We consequently had to compare the relative acidities of these species on the basis of our calculations, which we chose to do through the building of a relative acidity scale.

In order to make sure that we do not diverge too much from reality, we first build this acidity scale in dimethyl sulfoxide (DMSO), which dielectric constant (47.24 at 293.2 K) is stronger than that of THF (7.52 at 293.2 K) [31], but which is also aprotic, and for which numerous experimental values are available within the literature. DFT calculations in DMSO are performed using the default DMSO parametrization of the SMD implicit solvent model. 


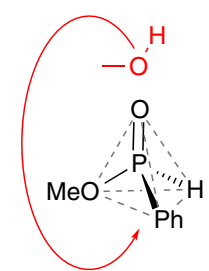

F1

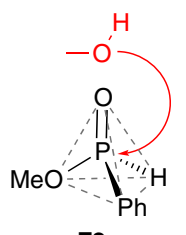

F2

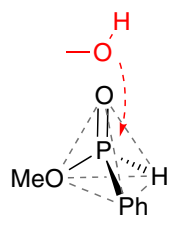

F3

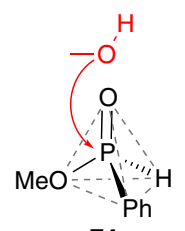

F4
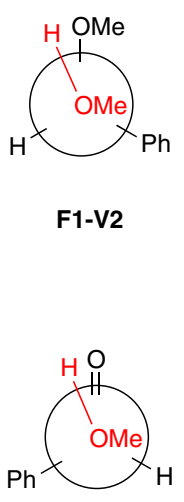

F2-V1

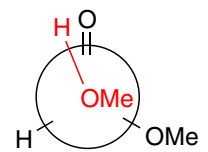

F3-V1

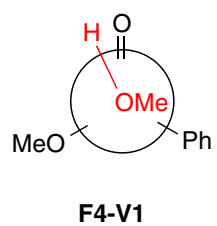

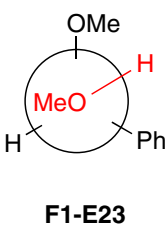
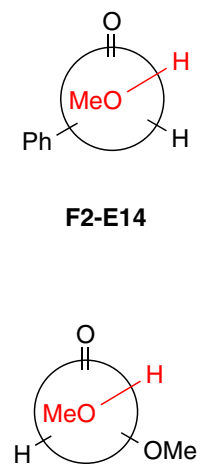

F3-E12

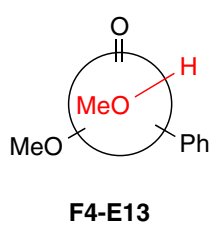

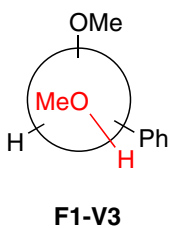

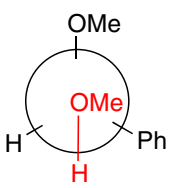

F1-E34

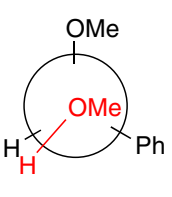

F1-V4
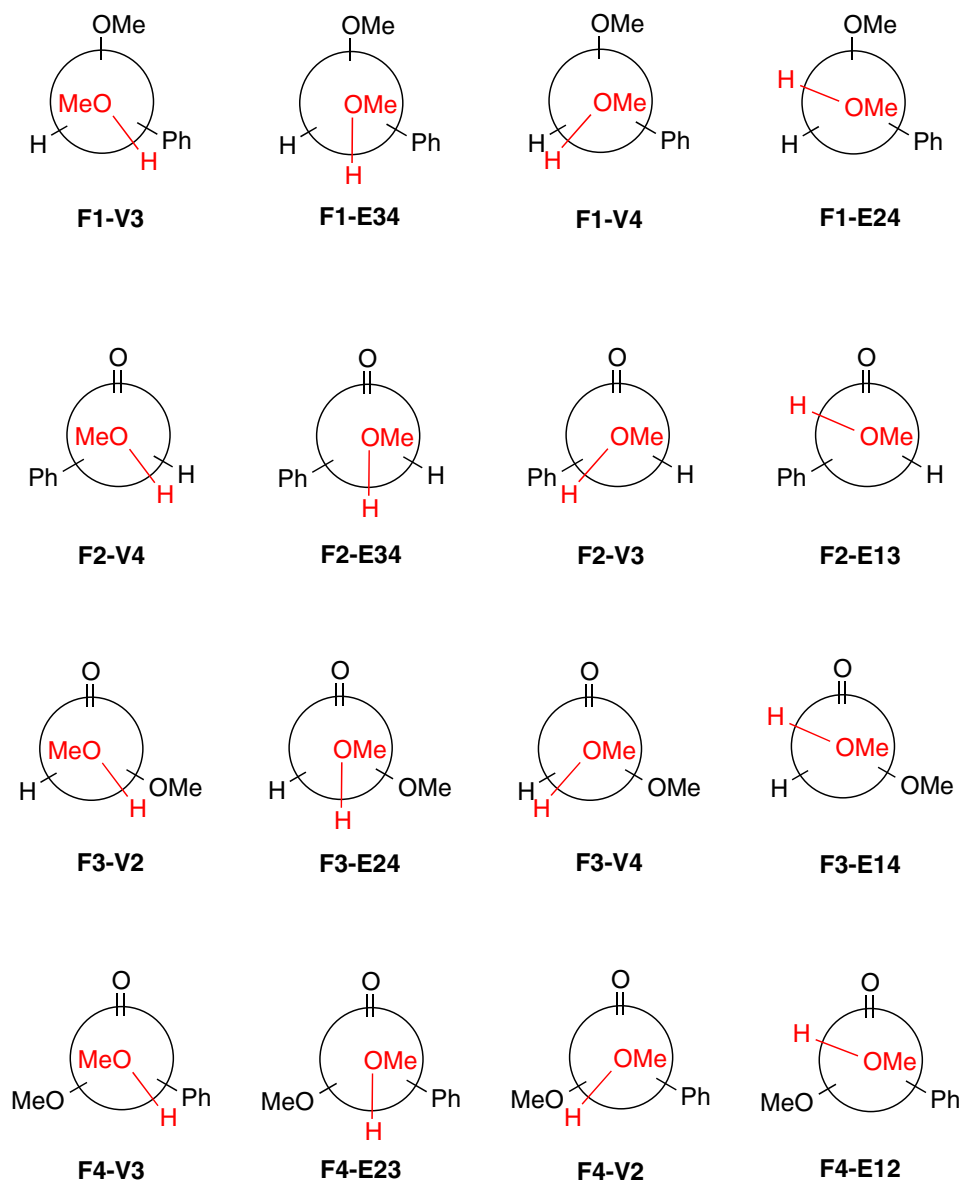

Fig. 5 Representation of the 24 investigated nucleophilic attacks of methanol on methyl hydrogeno-phenylphosphinate

Predicting pKa scales is not something simple, and there is at the moment no consensus about the best way to perform such calculations, which means also that no successwarrantied ready-to-use procedure is available for such calculations. Additionally, in the present case, since the proton exchange reaction takes place between neutral reactants, it produces a charge separation, which leads to a large overestimation of the energy required for this reaction. We decided to go around the problem by studying proton transfer reactions in which no charge separation occurs.

This procedure eliminates the charge separation problem, but generates two parallel pKa scales, one for negatively charged reactions and one for positively charged reactions. In order to answer the initial question of a possible proton transfer between neutral species at the equilibrium, these parallel scales have to be merged, which is achieved by scaling them using experimental data.

Scaling both calculated pKa scales, even differently, during this process is arbitrary. To our knowledge, there is no theoretical reason why it should work, and this is the reason why we are testing it on experimental data before concluding.
We first chose two acidobasic couples as references, which pKa are known in DMSO: $\mathrm{MeOH} / \mathrm{MeO}^{-}$(29.0 at $298 \mathrm{~K}$ [32]) and $\mathrm{Et}_{3} \mathrm{NH}^{+} / \mathrm{Et}_{3} \mathrm{~N}(9.0$ at $298 \mathrm{~K}[33,34])$. Proton transfer reaction standard Gibbs free energies $\Delta_{\mathrm{r}} \mathrm{G}^{\circ}$ are calculated for the following reactions, in which no charge separation takes place.

$\mathrm{MeOH}+\mathrm{A}^{-} \rightleftharpoons \mathrm{MeO}^{-}+\mathrm{AH}$

$\mathrm{Et}_{3} \mathrm{NH}^{+}+\mathrm{B} \rightleftharpoons \mathrm{Et}_{3} \mathrm{~N}+\mathrm{BH}^{+}$

This gives access to the $\mathrm{pKa}$ of couples $\mathrm{AH} / \mathrm{A}^{-}$and $\mathrm{BH}^{+} / \mathrm{B}$ relative to the known pKa of couples $\mathrm{MeOH} / \mathrm{MeO}^{-}$and $\mathrm{Et}_{3} \mathrm{NH}^{+} / \mathrm{Et}_{3} \mathrm{~N}$ through the following formulae.

$\mathrm{pKa}_{\text {unkown }}=\mathrm{pKa}_{\text {reference }}-\frac{\Delta_{\mathrm{r}} \mathrm{G}^{\circ}}{\mathrm{RT} \ln (10)}$

The resulting $\mathrm{pKa}$ scale is however distended, which means that the calculated $\mathrm{pKa}$ values are in the right order, but too far away from each other when compared to available experimental data (see Supporting material for details). Two additional acidobasic couples are then selected, which 
structures are sufficiently different from both reference couples, and which pKa in DMSO are known, to estimate the scaling factors that have to be applied to both pKa scales. Finally, a third pair of acidobasic couples is used, which structures are again sufficiently different from other used couples, and which pKa in DMSO are known, to check the validity of the estimated scale.

Couples used for estimating the scaling factors are $\mathrm{AcOH} / \mathrm{AcO}^{-}$(12.6 at $298 \mathrm{~K}$ [35]) and 1-hydroxypyridinium/ 1-oxopyridinium (1.63 at $298 \mathrm{~K}$ [36]). The scaling factors for the negatively and positively charged scales are estimated to 0.33 and 0.26 respectively. Couples used to check the validity of the resulting scale are benzophenone oxime and its corresponding deprotonated form (20.1 at $298 \mathrm{~K}$ [37]) and Quinuclidine $\mathrm{H}^{+} /$Quinuclidine (9.8 at $298 \mathrm{~K}$ [38]). The resulting acidity scale is represented in Fig. 6.

It can be seen in Fig. 6 that both couples used to test the validity of the estimated $\mathrm{pKa}$ scale are almost at the right position, 9.1 instead of 9.8 for Quinuclidine $\mathrm{H}^{+} /$Quinuclidine and 17.9 instead of 20.1 for benzophenone oxime and its corresponding deprotonated form. This is very reasonable on a scale that runs from -10 up to 30 . In particular, this degree of precision is highly sufficient to conclude that MeHP and methanol cannot deprotonate each other spontaneously, since the corresponding couples differ about $26 \mathrm{pKa}$ units in case methanol deprotonate MeHP, and about 33 pKa units in case MeHP deprotonate methanol. Moreover, since the dielectric constant of THF is significantly lower than that of DMSO, it is even more unlikely in THF that both neutral MeHP and methanol molecules deprotonate each other and generate separated ions.

The conclusion of this short acidobasic study is consequently that MeHP and methanol only exist as neutral molecules in the reactive mixture. We then confidently head for nucleophilic attacks as the only reactions that may take place when both molecules collide.

\section{Nucleophilic attacks}

Modeling the 24 considered approaches using PM6 generates only six reaction pathways. Taking dispersion into account through the PM6-D3H4 method leads to the same result (numerical details are provided as Supplementary material). In all these pathways, the hydrogen atom of the methanol molecule exhibits a hydrogen bond with one of both oxygen atoms that are bonded to the phosphorus center, either with the V1 doubly bonded oxygen atom (F2-V1, F3-V1, F4-V1) or with the V2 methoxy oxygen atom (F1-V2, F3-V2, F4-V2). The existence of these six reaction pathways is confirmed by DFT calculations, in which reactants, products and transition structures, obtained at the PM6 level have been reoptimized.

Both series, i.e., V1 and V2, behave very differently. V1 attacks consist of syn-additions of the methanol molecule on the $\mathrm{P}=\mathrm{O}$ double bond. They lead to penta-coordinated intermediates 9 to 11, through transition structures TS4 to TS6. In these mechanisms, the methoxy part of the methanol molecule is added to the phosphorus center, while the hydrogen atom is transferred to the oxygen atom V1 that was initially doubly bonded to the phosphorus center (left side of Fig. 7). These penta-coordinated intermediates can subsequently give access to racemization or transesterification products by eliminating the second methoxy substituent that is held by the phosphorus center through a mechanism that is similar to the addition mechanism. In case of a transesterification reaction, the configuration of the phosphorus center is expected to be inverted, except if the penta-coordinated intermediates can undergo pseudorotations, which would possibly lead to a complete loss of stereoselectivity. This process is detailed within the next section.

In V2 attacks, the alcohol exchange reaction on the phosphorus center occurs in a single step. The hydrogen atom of the methanol molecule is transferred to the methoxy substituent V2 that is held by the phosphorus center. This substituent

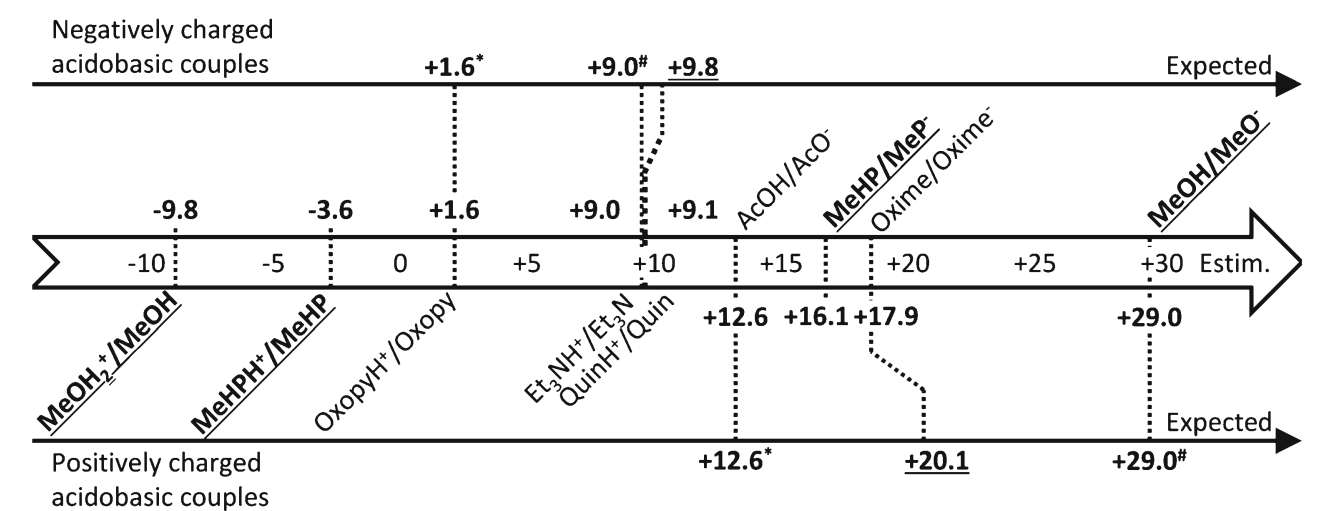

Fig. 6 Estimated acidity scale in DMSO (middle) and comparison with expected values from literature for negatively charged acidobasic couples (top) and positively charged acidobasic couples (bottom). Values used as anchor points are marked with \# $\left(\mathrm{MeOH} / \mathrm{MeO}^{-}\right.$at 29.0 and $\mathrm{Et}_{3} \mathrm{NH}^{+} / \mathrm{Et}_{3} \mathrm{~N}$ at 9.0). Those used for calculating scaling factors are marked with *
(AcOH/AcO at 12.6 and 1-hydroxypyridinium/1-oxopyridinium at 1.6). Those used as tests are underlined (OXIME at 20.1 and Quinuclidine ${ }^{+}$/ Quinuclidine at 9.8). Couples with particular interests within the present study are bolded and underlined 

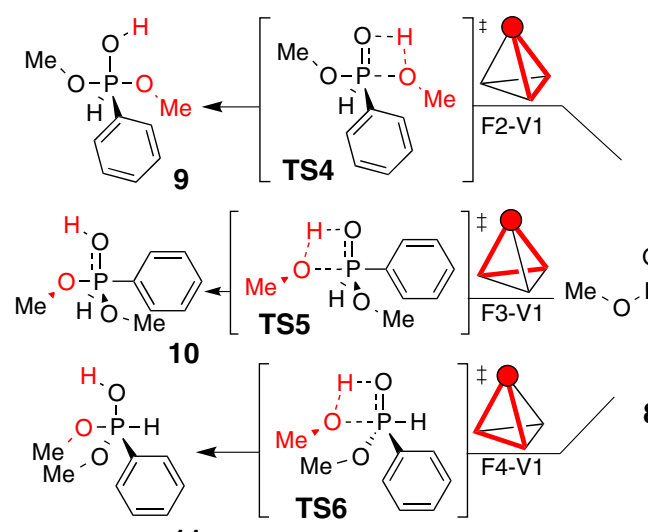

11

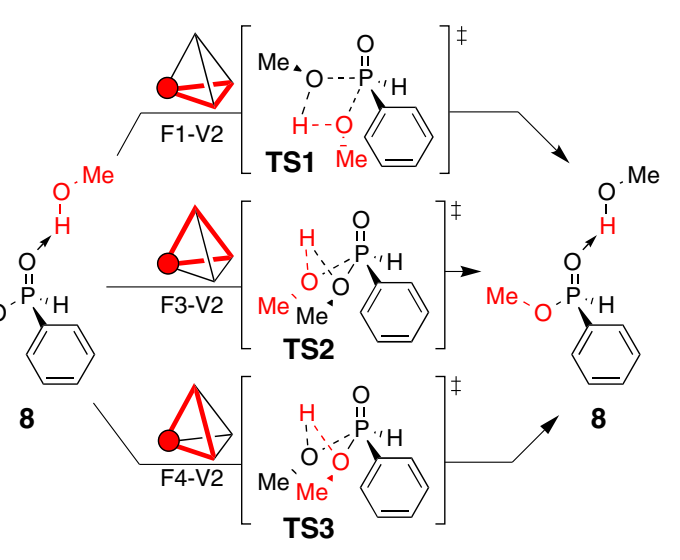

Fig. 7 First activated steps of the only six relevant mechanisms, among the 24 investigated ones, that actually take place during the nucleophilic attack of methanol on MeHP. Structure 8, which is used here as a common energetic reference for all investigated routes, is the association with the

lowest standard Gibbs free energy between methanol and MeHP. In this structure, the alcoholic hydrogen atom of methanol builds a hydrogen bond with the oxygen atom that is doubly bonded to the phosphorus center (V1)

is subsequently eliminated, while the methoxy part of the methanol molecule is added to the phosphorus center (right side of Fig. 7). No racemization takes place through this mechanism. In the case of a transesterification reaction, the configuration of the phosphorus center remains unchanged.

As can be seen in Figs. 7 and 8, V2 mechanisms are associated with much higher transition standard Gibbs free energies (F1-V2, TS1: $268 \mathrm{~kJ} \mathrm{~mol}^{-1}$; F3-V2, TS2: $205 \mathrm{~kJ} \mathrm{~mol}^{-1}$; F4-V2, TS3: $204 \mathrm{~kJ} \mathrm{~mol}^{-1}$ ) than V1 mechanisms (F2-V1, TS4: $113 \mathrm{~kJ} \mathrm{~mol}^{-1}$, F3-V1, TS5: $133 \mathrm{~kJ} \mathrm{~mol}^{-1}$ and F4-V1, TS6: $130 \mathrm{~kJ} \mathrm{~mol}^{-1}$ ). Additionally, within the $\mathrm{V} 1$ series, the F2-V1 (TS4) mechanism, in which the methoxy part of the methanol molecule is added on the opposite side of the methoxy substituent already bonded to the phosphorus center, exhibits a significantly lower transition standard Gibbs free energy (113 $\left.\mathrm{kJ} \mathrm{mol}^{-1}\right)$ than both F3-V1 (TS5) and F4-V1 (TS6) mechanisms $\left(133 \mathrm{~kJ} \mathrm{~mol}^{-1}\right.$ and $\left.130 \mathrm{~kJ} \mathrm{~mol}^{-1}\right)$. From a kinetic point of view, these differences are discriminating.

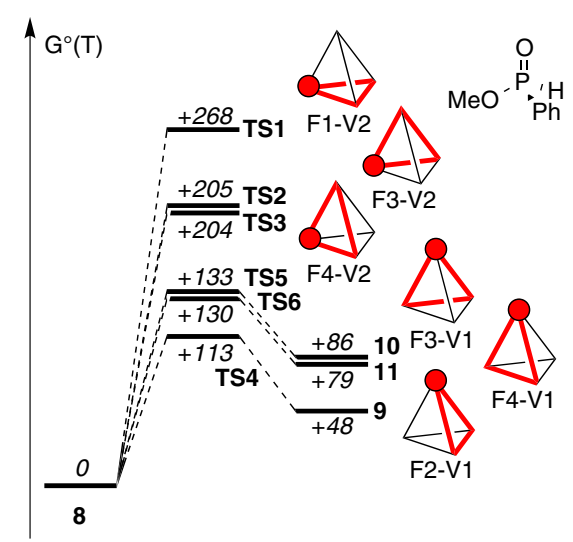

Fig. 8 Reaction and transition standard Gibbs free energies associated with the mechanisms represented in Fig. 7. Numerical values are calculated at $25{ }^{\circ} \mathrm{C}$ using DFT (SMD(THF)//M06-2X/6-31++G**) for solute standard states. Structure $\mathbf{8}$ is used here as an energetic reference. Energy unit: $\mathrm{kJ} \mathrm{mol}^{-1}$

Indeed, at room temperature, the resulting ratio between kinetic constants $\mathrm{k}_{\mathrm{F} 4-\mathrm{V} 1}$ and $\mathrm{k}_{\mathrm{F} 2-\mathrm{V} 1}$, which correspond to both lowest transition structures, using Eyring equation, is equal to $1.0510^{-3}$. Additionally, reaction intermediate 9, which is reached through attack F2-V1 (TS4) is significantly lower in energy, about $39 \mathrm{~kJ} \mathrm{~mol}^{-1}$ and $32 \mathrm{~kJ} \mathrm{~mol}^{-1}$ respectively, than intermediates 10 and $\mathbf{1 1}$ reached through attacks F3-V1 (TS5) and F4-V1 (TS6). Attack F2-V1 (TS4, 9) is consequently simultaneously associated with the lowest transition structure and to the lowest reached reaction intermediate.

We consequently conclude, from this comprehensive study, that the nucleophilic attack of methanol on MeHP consists of a syn-addition of the methoxy part of the methanol molecule on the $\mathrm{P}=\mathrm{O}$ double bond, on the opposite side, with respect to the phosphorus center, of the methoxy substituent (attack F2-V1, transition structure TS4, reaction intermediate 9).

\section{Further evolution of the pentacoordinated intermediate}

After methanol is added to MeHP, the resulting pentacoordinated intermediate 9, can evolve backward, and eliminate the methanol molecule that was just inserted.

On the other hand, intermediate $\mathbf{9}$ can also evolve forward and lead to the elimination of the methoxy group that was initially bonded to the phosphorus center. This process first consists of small conformational changes. The methoxy group that was initially bonded to the phosphorus center rotates (TS7 and TS8), and subsequently rotates the hydroxyl group (TS9). The hydrogen atom of this group is initially directed toward the incoming methoxy group, and rotates toward the leaving methoxy group. The methoxy group that is expected to remain attached to the phosphorus center then rotates twice (TS8' and TS7'), and a methanol molecule is finally eliminated (TS4'). A full picture of the mechanism is provided in Fig. 9. 


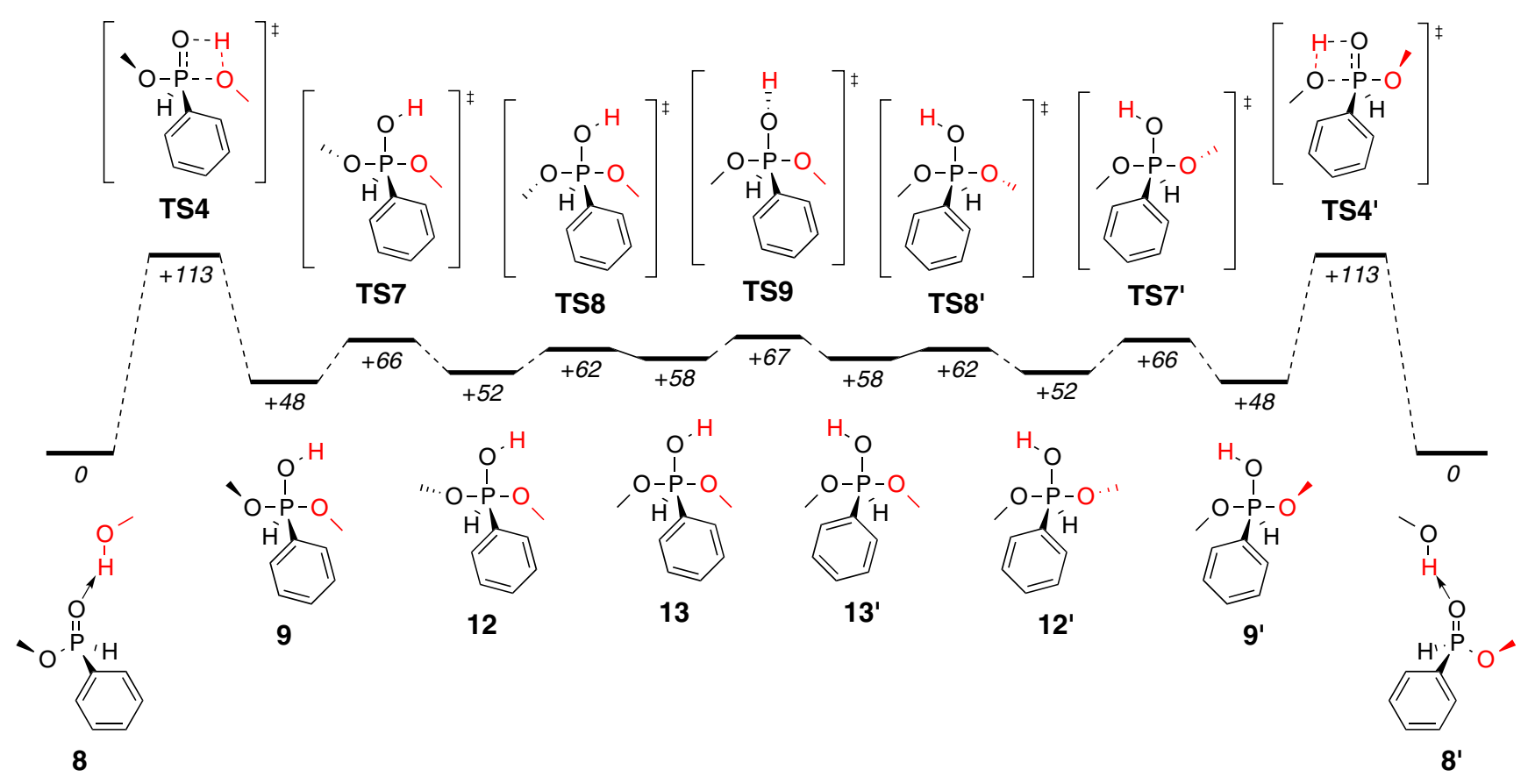

Fig. 9 Nucleophilic attack of methanol on MeHP: mechanism with the lowest energy profile. Primes designate enantiomeric structures. Standard Gibbs free energies (italic, $\mathrm{kJ} \mathrm{mol}^{-1}$ ) are calculated at $25^{\circ} \mathrm{C}$ using DFT

In TS9, the hydroxylic hydrogen atom rotates over the hydrogen atom that is held by the phosphorus center. In principle, it could actually also rotate over the phenyl group. This route is however strongly unfavorable. The corresponding transition structure TS9b is indeed $38 \mathrm{~kJ} \mathrm{~mol}^{-1}$ higher than TS9. This result finds its origin in the flexibility of the pentacoordinated intermediate and in the fact that the over-H region is much less sterically hindered than the over-phenyl region. These particularities allow both methoxy groups to accompany and stabilize through H-bonds the rotating hydrogen atom during its whole rotation over the H-side, which is not possible over the phenyl-side due to the steric hindrance induced by the phenyl group.

Along the energy profile, all transition structures TS7 to TS7' are much lower in energy, with a maximum of $67 \mathrm{~kJ}$ $\mathrm{mol}^{-1}$, than the transition structures TS4 and TS4' (113 kJ $\mathrm{mol}^{-1}$ ). Statistically, this means that the whole conformational space ranging from intermediate 9 to intermediate $9^{\prime}$ becomes thermalized long before any backward or forward alcohol elimination takes place. In other words, kinetically, intermediates 9 to $9^{\prime}$ are permanently at the equilibrium and act as a single reaction intermediate, whereas transition structures TS4 and TS4' are rate determining for the overall alcohol exchange reaction.

Finally, it can be observed in Fig. 9 that this mechanism is fully symmetric with respect to TS9. This situation is of course due to the fact that both incoming and leaving alcohol molecules are represented by methanol. In the case of a transesterification, both involved alcohol molecules are

(SMD(THF)//M06-2X/6-31++G**) for solute standard states. Structure $\mathbf{8}$ is used as an energetic reference

different and energies on both sides of TS9 may consequently differ. We can even imagine that, in extreme cases, the incoming alcohol can be added, but reacts finally backward because the departure of the leaving alcohol is kinetically hindered.

The backward elimination process preserves a priori the stereochemistry of the phosphorus center, whereas the alcohol exchange mechanism inverts a priori this stereochemistry. This result might however be very different if the pentacoordinated intermediate undergoes Berry pseudorotations previous to the backward or forward elimination. This possibility is investigated in detail within the next section.

\section{Berry pseudo rotations of the pentacoordinated intermediate}

Molecular structures containing triangle-based bi-pyramidal pentacoordinated phosphorus centers are known for their ability to undergo Berry pseudorotations, in which two equatorial ligands switch their positions with both apical ligands [39]. Technically, in such a pentacoordinated structure, if all five ligands are different, there are 20 different way of positioning them around the phosphorus center and the ligands undergo 30 different pseudorotations. In our precise case however, both methoxy ligands are identical, which reduces the possibilities down to ten different structures, among which three are enantiomeric pairs and 15 pseudorotations (Fig. 10).

In Fig. 9, within the previous section, every reaction intermediate corresponds to the structure that is directly obtained 

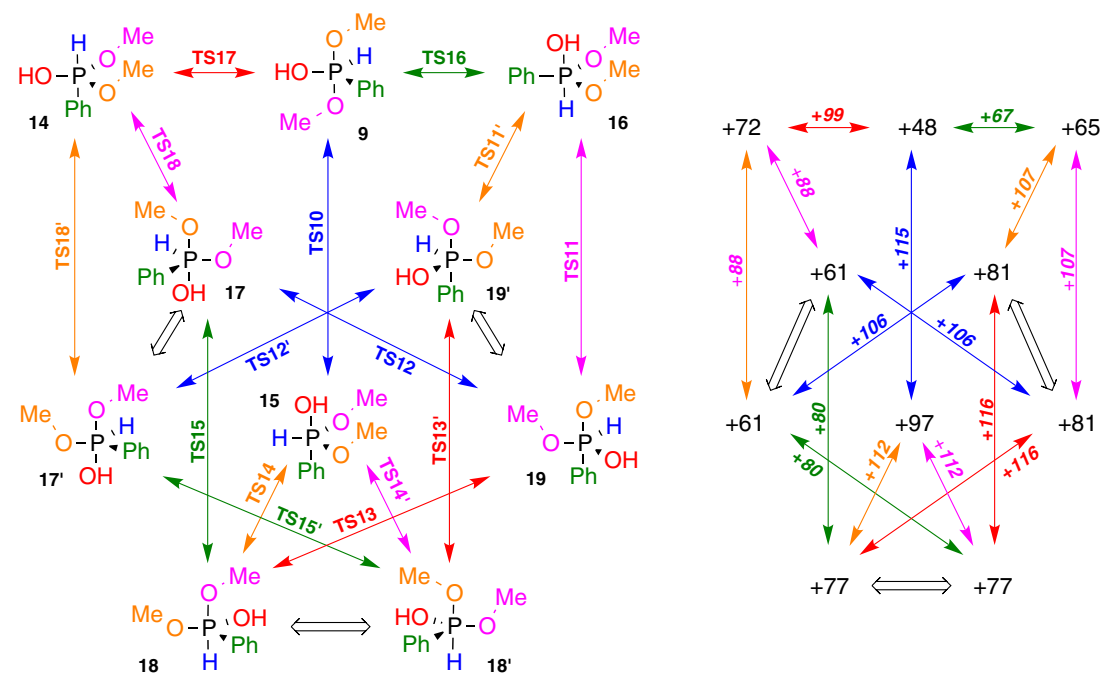

Fig. 10 Left: Complete list of all ten pentacoordinated intermediates 9 and 14 to 19 that can be transformed into each other through pseudorotations and all 15 pseudorotations that bind them. Wide double arrows represent enantiomeric relationships. The color of each arrow representing a pseudorotation is assorted to the color of the ligand that

remains in equatorial position during the pseudorotation. Right: Standard Gibbs free energies of all reaction intermediates (straight and black) and transition structures (italic and colored) represented on the left hand side of the figure (energetic reference: structure 8). Energy unit: $\mathrm{kJ} \mathrm{mol}^{-1}$

from IRC calculations. In Fig. 10, the situation is different. It is indeed shown, within the previous section, that the energies involved in methyl, phenyl, and hydroxyl rotations (Fig. 9) are small if compared to the energies involved in pseudorotations (Fig. 10) and in methanol eliminations (Fig. 9). Not taking them explicitly into account has consequently no influence over the predicted global kinetic of the alcohol exchange reaction, and conformers that differ only by such rotations are consequently considered in Fig. 10 as single species. For example, intermediate $\mathbf{1 8}$ is surrounded by transition structures TS13, TS14, and TS15. IRC calculations lead, from these transition structures, to intermediates 18-IRC13, 18-IRC14, and 18-IRC15 that only differ by methyl, phenyl, and/or hydroxyl rotations. Intermediate $\mathbf{1 8}$ simply designates the most stable of theses conformers.

From the standard Gibbs free energies reported in Fig. 10, it appears that not all ligands have the same affinity for apical positions. From the available numerical values $(\mathbf{9}, 17,18,19)$, the following apicophilicity scale is established, OMe > $\mathrm{OH}>\mathrm{H}>\mathrm{Ph}$. This result is actually in agreement with previous observations [40-42], which we take as a confirmation of the validity of our modeling. Note that apicophilicities are numerically not additive, which is due to hydrogen bonds and other additional electronic effects.

The most interesting result that comes out of Fig. 10 is that, from intermediate $\mathbf{9}$, pseudorotations are actually competitive (highest calculated TS: $116 \mathrm{~kJ} \mathrm{~mol}^{-1}$ ) with backward and forward methanol eliminations $\left(113 \mathrm{~kJ} \mathrm{~mol}^{-1}\right)$. This means that the penta-coordinated intermediate obtained after an alcohol molecule has been added to an alkyl hydrogeno-phenylphosphinate molecule may racemize before any alcohol molecule is eliminated from this intermediate. The routes that lead to such a

racemization through pseudorotations are represented in Fig. 11. Several possible racemization routes actually lead from 20, which is equivalent to 9 if $\mathrm{R}_{1}=\mathrm{R}_{2}=\mathrm{OMe}$, to 21, which is its enantiomeric version, for example 20-28-27-32-33-38-37-21 (highest calculated TS: $116 \mathrm{~kJ} \mathrm{~mol}^{-1}$ between 27 and 32).

It is of course expected that the exact nature of both involved alkoxy groups may significantly influence the actual transition standard Gibbs free energies associated with the rate determining steps of the alcohol insertion, the alcohol elimination, and the pseudorotations. Depending on these values, five scenarios can take place. First, the energy barrier associated with the alcohol insertion is high enough to prevent it within the conditions of the experiment. In such a case, the alkyl hydrogeno-phenylphosphinate is chemically and stereochemically stable. Second, the energy barrier associated with the alcohol insertion is low enough to make it possible within the conditions of the experiment. Then, the resulting penta-coordinated intermediate is either stereochemically stable or inverts through pseudorotations. Finally, the energy barrier associated with the alcohol elimination is either too high to make it possible, and the only possible alcohol elimination is consequently backward, or the energy barrier is low enough to make the forward alcohol elimination possible. In the first case, the alkyl hydrogeno-phenylphosphinate is chemically stable, but may racemize through pseudorotations. In that case, it can even be imagined that a very small amount of alcohol may lead to the racemization of the alkyl hydrogeno-phenylphosphinate molecule without apparent reactivity. In the second case, the alkyl hydrogeno-phenylphosphinate is chemically unstable, i.e., its alkyl group has been changed, and the phosphorus center has been inverted, or has possibly racemized through pseudorotations (Fig. 12). 
Fig. 11 Complete list of 20 pentacoordinated intermediates that can be transformed into each other through pseudorotations in case both alkoxy groups $\left(\mathrm{R}_{1}\right.$ and $\mathrm{R}_{2}$ ) are different. The color of each line representing a pseudorotation is assorted to the color of the ligand that remains in equatorial position during the pseudorotation. The corresponding structures in the case $\mathrm{R}_{1}=\mathrm{R}_{2}=$ OMe are provided between brackets

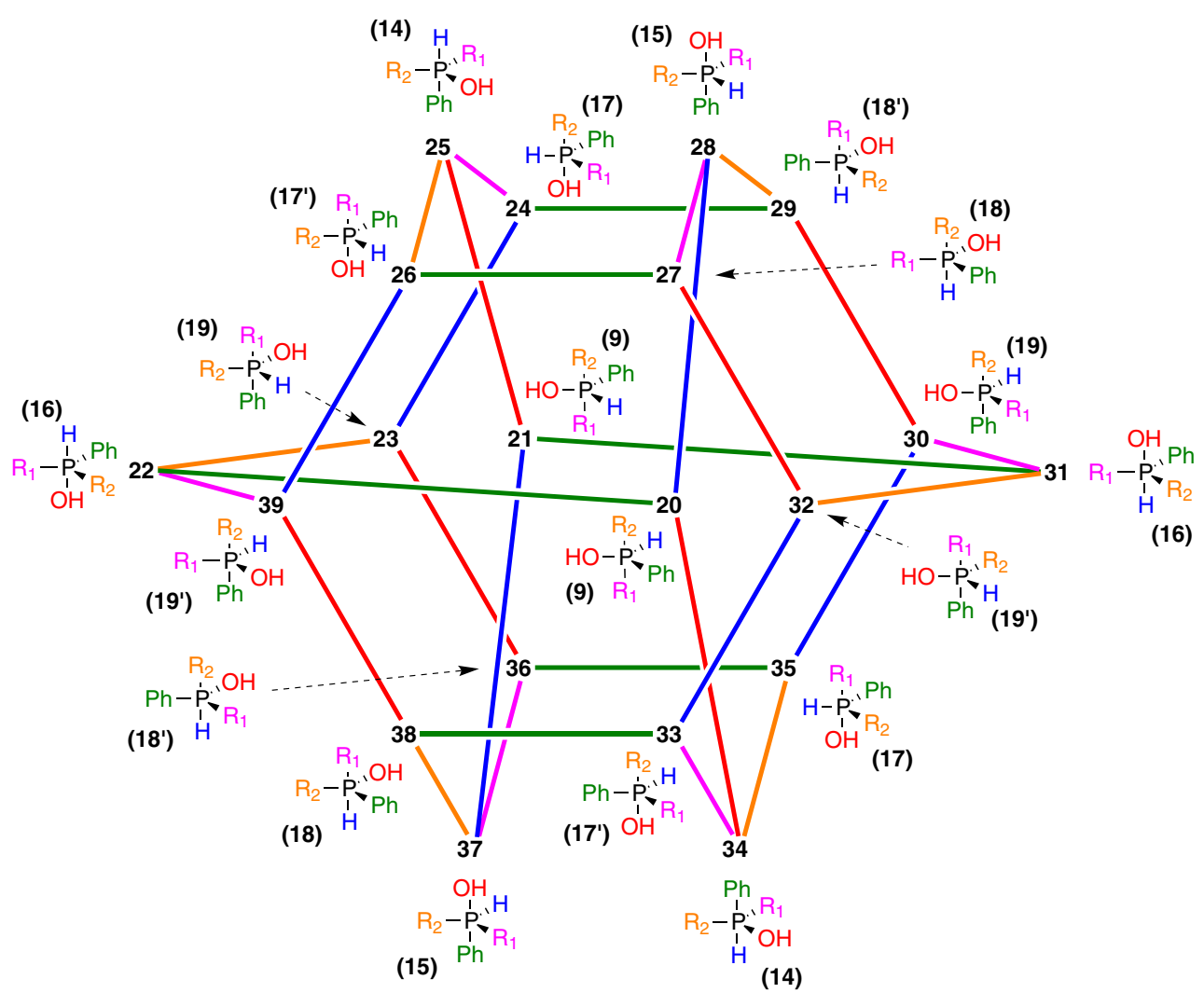

\section{Association and dissociation of reactants and products}

Intermediate 8, which simply corresponds to the association of both reactants through an $\mathrm{H}$-bond, has been used as an energetic reference.

This choice has voluntarily been made on account of our expertise in this area, which has proven to us that estimating precisely such energies in condensed phase is a tough task, especially due to the difficulty of correctly estimating translational entropies in solution. We consequently prefer to

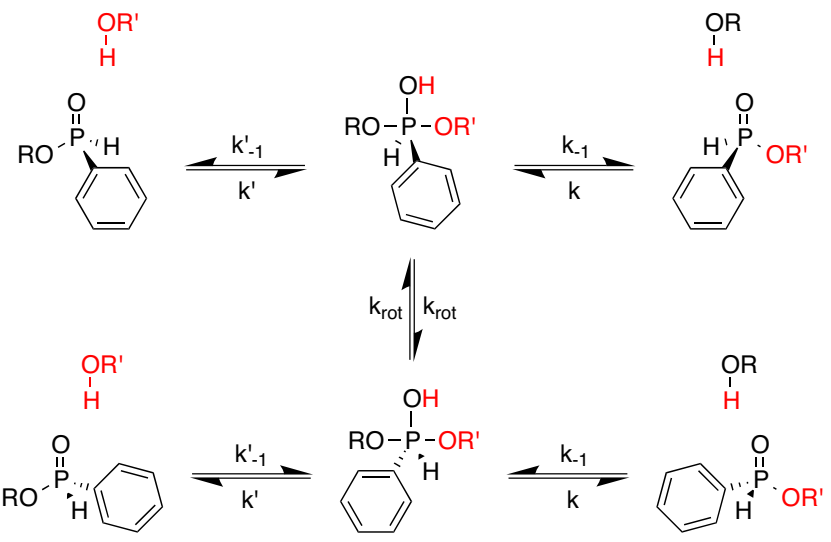

Fig. 12 Schematic summary of all possible formal reactive routes within the framework of a nucleophilic attack of an alcohol molecule on an alkyl hydrogeno-phenylphosphinate molecule estimate them separately from the reaction mechanism and avoid any contamination of the calculated barrier by those uncertain data.

In the present case, the reaction standard Gibbs free energy corresponding to the association of MeHP $\mathbf{1}$ and methanol $\mathbf{2}$ into intermediate 8 at $25^{\circ} \mathrm{C}$ obtained from DFT (SMD(THF)// M06-2X/6-31++G**) is $8 \mathrm{~kJ} \mathrm{~mol}^{-1}$, which leads to an overall energy barrier of $121 \mathrm{~kJ} \mathrm{~mol}^{-1}$. This value is not discussed further here, but within the upcoming discussion, where its reliability is explicitly checked.

\section{Experimental measurements}

Methyl hydrogeno-phenylphosphinate is chemically unstable and denatures faster than it racemizes. We consequently ran the experiments with the smallest alcohol after methanol, and experimentally monitored the racemization kinetics of ethyl hydrogeno-phenylphosphinate (EtHP) in the presence of ethanol.

We used pure ethanol as solvent and measured the racemization kinetics at its boiling temperature $\left(78 \pm 1{ }^{\circ} \mathrm{C}\right)$. Four experiments have been performed, where the phosphinate concentration has been varied from $1.3010^{-4} \mathrm{~mol} \mathrm{~L}^{-1}$ to $1.3110^{-2} \mathrm{~mol} \mathrm{~L}^{-1}$. The racemization kinetics have been followed using chiral HPLC (see Experimental section). Raw experimental data are reported in Tables 1 and 2. 
Table 1 Synthetic description of racemization kinetic experiments. Solvent: ethanol. Temperature: $78 \pm 1{ }^{\circ} \mathrm{C}$ (ethanol boiling point)

\begin{tabular}{lll}
\hline Experiment & EtHP concentration $\left(\mathrm{mol}_{\mathrm{L}}^{-1}\right)$ & Initial enantiomeric excess (\%) \\
\hline 1 & $(1.31 \pm 0.04) 10^{-2}$ & $97.9 \pm 1.0$ \\
2 & $(1.31 \pm 0.04) 10^{-2}$ & $97.1 \pm 1.0$ \\
3 & $(2.60 \pm 0.07) 10^{-4}$ & $96.0 \pm 1.0$ \\
4 & $(1.30 \pm 0.04) 10^{-4}$ & $95.6 \pm 1.0$ \\
\hline
\end{tabular}

\section{Kinetic modeling}

Both incoming and leaving alcohols used experimentally are identical and the overall kinetic scheme described in Fig. 12 then simplifies into a single reactive pathway with, formally, a single reaction intermediate and two symmetric transition structures. On the basis of the DFT modeling, in which the pentacoordinated intermediates are shown to be significantly higher in energy than the reactants and products $\left(9\right.$ is $48 \mathrm{~kJ} \mathrm{~mol}^{-1}$ higher than 8 at $25{ }^{\circ} \mathrm{C}$ ), the quantity of the formally unique reaction intermediate is assumed permanently negligible with respect to the quantities of the reactants and products. It is then easily shown that the racemization kinetics obey the following law, in which ee(t) represents the enantiomeric excess at time $\mathrm{t}$, and $\mathrm{k}$ the kinetic constant associated with the reaction step that leads from separated ethanol and EtHP molecules to the reaction intermediate, as defined in Fig. 12.

$\frac{d e e(t)}{d t}=-k \frac{[\mathrm{EtOH}]}{c^{\circ}} e e(t)$

The racemization reaction produces exactly as much ethanol as it consumes. The concentration of ethanol consequently remains constant, and this last differential equation integrates as follows, where $e_{0}$ represents the initial enantiomeric excess.

$e e(t)=e e_{0} \exp \left(-k \frac{[\mathrm{EtOH}]}{c^{\circ}} t\right)$

Every single data point reported in Table 2 can consequently be converted into a measure of $\mathrm{k}$. To do so, the actual concentration of ethanol is required, which we calculate from the density of ethanol at its boiling point $\left(16.06 \pm 0.02\right.$ mol. $\left.\mathrm{L}^{-1}\right)$ [31]. The resulting values of $\mathrm{k}$ are reported in Fig. 13, along with the fitted value of $\mathrm{k}$ for each single experiment. Fitting is achieved by minimizing the average quadratic deviation between the measured and the predicted values of $k$. The inverse of the square of the absolute uncertainty is used for weighting each fitted data.
Finally, transition standard Gibbs free energies are extracted from the fitted $k$ values using Eyring Eq. (3). These energies are reported in Table 3.

$\Delta_{r} G^{*}=-\mathrm{R} \operatorname{Tln}\left(\frac{k h}{k_{B} T}\right)$

Table 2 Data points that have been collected during racemization kinetic measurements. "Exp" refers to experiments described in Table 1

\begin{tabular}{|c|c|c|c|}
\hline Data & Exp & Duration (min) & ee $(\%)$ \\
\hline 1 & 1 & $341 \pm 1$ & $96.0 \pm 1.0$ \\
\hline 2 & 1 & $1331 \pm 1$ & $90.0 \pm 1.0$ \\
\hline 3 & 1 & $1707 \pm 1$ & $87.7 \pm 1.0$ \\
\hline 4 & 1 & $2777 \pm 1$ & $80.7 \pm 1.0$ \\
\hline 5 & 1 & $2834 \pm 1$ & $80.4 \pm 1.0$ \\
\hline 6 & 1 & $3234 \pm 1$ & $78.6 \pm 1.0$ \\
\hline 7 & 1 & $4205 \pm 1$ & $74.0 \pm 1.0$ \\
\hline 8 & 1 & $4612 \pm 1$ & $72.0 \pm 1.0$ \\
\hline 9 & 1 & $5695 \pm 1$ & $66.4 \pm 1.0$ \\
\hline 10 & 1 & $6118 \pm 1$ & $64.8 \pm 1.0$ \\
\hline 11 & 1 & $7178 \pm 1$ & $60.9 \pm 1.0$ \\
\hline 12 & 2 & $97 \pm 1$ & $96.5 \pm 1.0$ \\
\hline 13 & 2 & $1151 \pm 1$ & $89.9 \pm 1.0$ \\
\hline 14 & 2 & $1598 \pm 1$ & $87.0 \pm 1.0$ \\
\hline 15 & 2 & $2587 \pm 1$ & $80.3 \pm 1.0$ \\
\hline 16 & 3 & $68 \pm 1$ & $95.8 \pm 1.0$ \\
\hline 17 & 3 & $1086 \pm 1$ & $91.3 \pm 1.0$ \\
\hline 18 & 3 & $1510 \pm 1$ & $89.7 \pm 1.0$ \\
\hline 19 & 3 & $2491 \pm 1$ & $85.7 \pm 1.0$ \\
\hline 20 & 3 & $2968 \pm 1$ & $83.2 \pm 1.0$ \\
\hline 21 & 3 & $3901 \pm 1$ & $80.1 \pm 1.0$ \\
\hline 22 & 4 & $404 \pm 1$ & $94.1 \pm 1.0$ \\
\hline 23 & 4 & $1339 \pm 1$ & $90.3 \pm 1.0$ \\
\hline 24 & 4 & $1807 \pm 1$ & $88.2 \pm 1.0$ \\
\hline 25 & 4 & $2970 \pm 1$ & $83.7 \pm 1.0$ \\
\hline 26 & 4 & $4299 \pm 1$ & $78.9 \pm 1.0$ \\
\hline 27 & 4 & $6124 \pm 1$ & $73.3 \pm 1.0$ \\
\hline 28 & 4 & $7269 \pm 1$ & $68.9 \pm 1.0$ \\
\hline 29 & 4 & $9974 \pm 1$ & $61.2 \pm 1.0$ \\
\hline
\end{tabular}




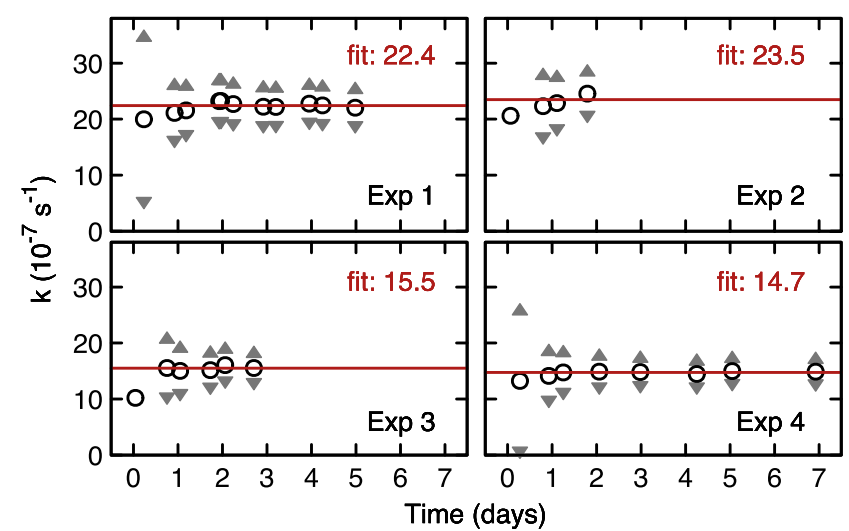

Fig. 13 Values of k obtained from the experimental data listed in Table 1 (circles). Triangles represent the associated uncertainty ranges. Horizontal red lines are obtained by fitting $\mathrm{k}$ values with a constant. The uncertainties associated with the first data points of experiments 2 and 3 are larger than the vertical range used in the figure and the corresponding triangles are consequently not visible

\section{Discussion}

Two conclusions are immediately drawn from Fig. 13. First, measured $\mathrm{k}$ values are almost constant along every single experiment, which is exactly what is expected on the basis of the DFT modeling. Second, $\mathrm{k}$ is not fully uniform over all experiments, which is not expected from the DFT modeling, and actually slightly depends on the phosphinate concentration. Multiplying this concentration by about 100 (from experiment 4 to experiment 1) indeed increases $\mathrm{k}$ by about $50 \%$ (from $1.510^{-6} \mathrm{~s}^{-1}$ to $2.210^{-6} \mathrm{~s}^{-1}$ ).

Figure 14 shows that this dependency is actually reproducible (experiments 1 and 2 on the right-hand side of the figure) and is not an experimental artifact. This dependency indeed corresponds to an evolution of the transition standard Gibbs free energy that is significantly larger than its associated uncertainty (triangles in Fig. 14).

At the moment, from our sparse data, only hypothesis can reasonably be drawn to interpret this slight dependency of the transition standard Gibbs free energy with respect to the phosphinate concentration. Our proposal, on the basis of the acidity scale presented in Fig. 6, in which MeHP is shown to be simultaneously more basic and more acidic than methanol, is that EtHP here acts as an acido-basic catalyst for the

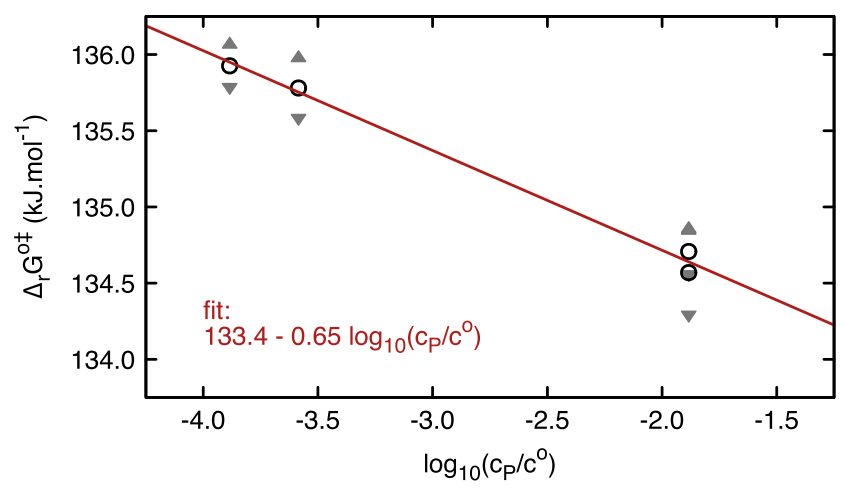

Fig. 14 Dependency of the transition standard Gibbs free energies $\left(\Delta_{\mathrm{r}} \mathrm{G}^{\mathrm{*}}\right)$ reported in Table 3 with respect to the phosphinate concentration $\left(\mathrm{c}_{\mathrm{P}}\right)$

reaction; such a catalysis may occur in different ways. A first EtHP molecule may, for example, activate the electrophilic character of the phosphorus center of a second EtHP molecule by building an H-bond with an oxygen atom that is directly bonded to the phosphorus center ( $=\mathrm{O}$ or $-\mathrm{OEt})$. It would be an acidic catalysis. Or it may activate the nucleophilic character of ethanol by building an H-bond with the hydrogen atom of the alcoholic hydroxyl group. It would be a basic catalysis. Investigating these hypotheses further necessitates a full dedicated study that is currently in progress and consequently out of the scope of this article.

The other aspect that now has to be investigated is the compatibility of the collected experimental data with the reaction mechanism that we proposed previously in this article. Considering the initial association of the reactants $\mathbf{1}$ and $\mathbf{2}$ into intermediate $8\left(\Delta_{\mathrm{r}} \mathrm{G}^{\circ}\left(25^{\circ} \mathrm{C}\right): 8 \mathrm{~kJ} \mathrm{~mol}^{-1}\right)$ and the energy barrier TS4 between intermediates 8 and $9\left(\Delta_{\mathrm{r}} \mathrm{G}^{\circ}\left(25^{\circ} \mathrm{C}\right)\right.$ : $113 \mathrm{~kJ}$ $\mathrm{mol}^{-1}$ ), the overall transition standard Gibbs free energy that is expected from the DFT modeling is $121 \mathrm{~kJ} \mathrm{~mol}^{-1}$ at $25^{\circ} \mathrm{C}$. This value changes a bit when the temperature is increased up to $78^{\circ} \mathrm{C}$ and reaches $128 \mathrm{~kJ} \mathrm{~mol}^{-1}$, with $13 \mathrm{~kJ} \mathrm{~mol}^{-1}$ that corresponds to the association of the reactants and $115 \mathrm{~kJ} \mathrm{~mol}^{-1}$ that corresponds to the energy barrier. This value is close to the $134-136 \mathrm{~kJ} \mathrm{~mol}^{-1}$ energy range that has been obtained experimentally, and we would like to conclude that our DFT model is in good agreement with the experimental data that we have collected.

However, before doing so, we have to check the reliability of the DFT modeling. This aspect is investigated by changing the functional, the implicit solvent model, and the basis set
Table 3 Transition standard Gibbs free energies extracted from the experiments described in Table 1 using the kinetic model deduced from the DFT modeling

\begin{tabular}{lll}
\hline Experiment & EtHP concentration $\left(\mathrm{mol}_{\mathrm{L}}^{-1}\right)$ & Transition standard Gibbs free energy $\left(\mathrm{kJ} \mathrm{mol}^{-1}\right)$ \\
\hline 1 & $(1.31 \pm 0.04) 10^{-2}$ & $134.7 \pm 0.2$ \\
2 & $(1.31 \pm 0.04) 10^{-2}$ & $134.6 \pm 0.3$ \\
3 & $(2.60 \pm 0.07) 10^{-4}$ & $135.8 \pm 0.2$ \\
4 & $(1.30 \pm 0.04) 10^{-4}$ & $135.9 \pm 0.2$ \\
\hline
\end{tabular}




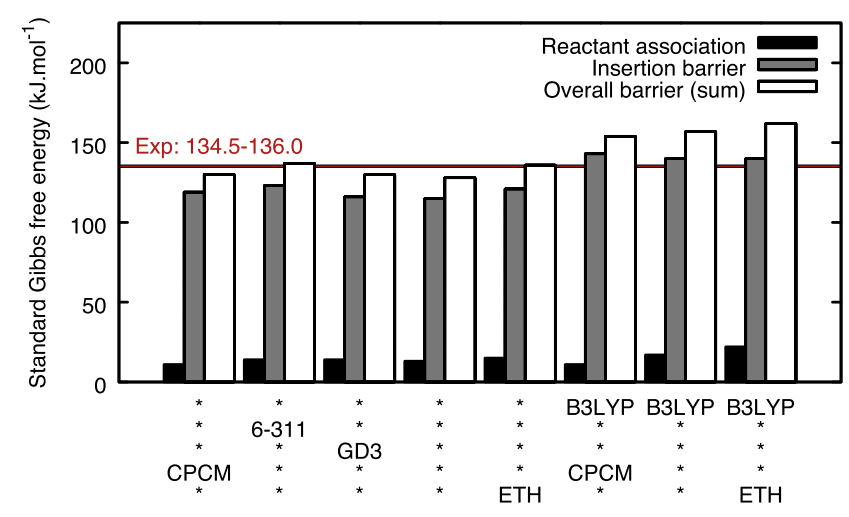

Fig. 15 Partial and overall transition standard Gibbs free energies of the rate determining step of the proposed mechanism, but recalculated using functional B3LYP, implicit solvent model CPCM, and basis set 6-311+ $+\mathrm{G}(\mathrm{d}, \mathrm{p})$ instead of M06-2X, SMD, and 6-31++G** (default values), or by adding GD3 as an empirical dispersion correction. * indicates that default values are used. ETH indicates that alkyl groups are ethyl groups

used for the key data of the DFT modeling, i.e., structures 1, 2, $\mathbf{8}$, and TS4, and by adding GD3 as an empirical dispersion correction. Additional modelings have been performed for structures $1,2,8$, TS4, and 9, but in which methyl groups have been replaced by ethyl groups. The corresponding structures are named 1-ETH, 2-ETH, 8-ETH, TS4-ETH, and 9-ETH and the associated numerical values are reported in Fig. 15 (numerical data are provided as Supporting material).

Several important conclusions can be drawn from these results. First, changing the implicit solvent model or adding GD3 as an empirical dispersion correction has almost no effect on the predicted energies. Second, the association energy is very similar $\left( \pm 4 \mathrm{~kJ} \mathrm{~mol}^{-1}\right)$ for all functional and solvent model combinations, which means that, on the contrary of what we had first frightened, this value seems reliable. Third, changing alkyl groups from methyl to ethyl slightly increases the calculated energy barriers $\left(+5 \sim 6 \mathrm{~kJ} \mathrm{~mol}^{-1}\right)$, but this variation is small if compared to that resulting from a change of functional. Indeed, changing the functional from M06-2X to B3LYP increases the overall energy barrier by about $25 \sim 30 \mathrm{~kJ} \mathrm{~mol}^{-1}$. This difference may first look gigantic if compared with the precision of the values obtained experimentally, but it is actually a reasonable difference within the framework of energy barrier predictions, and we can consequently conclude that the barriers predicted from DFT are consistent. Since they additionally occupy an energy range that includes the values obtained experimentally, we can confidently assess that the mechanism we proposed from DFT calculations is compatible with the experiment.

\section{Conclusions}

In this article, we explored in a systematic way all reactive routes that may be taken when an alcohol molecule meets an alkyl hydrogeno-phenylphosphinate molecule. It has been first shown that no acidobasic reaction takes place between these molecules. It has then been found that the alcohol molecule acts as a nucleophile and attacks the phosphinate molecule directly on the phosphorus center with a syn-addition mechanism, along a direction which is exactly opposite to the alkoxy group held by this atom. This attack leads to a pentacoordinated intermediate that is significantly more energetic than the reactants and can consequently not be isolated. This intermediate may racemize through Berry pseudorotations, and evolve, either toward the elimination of the alcohol molecule that has just been added, or toward the elimination, as an alcohol, of the alkoxy group that was initially held by the phosphinate molecule.

DFT modelings have been performed within the framework of a methanol molecule that attacks a methyl hydrogeno-phenylphosphinate molecule. According to these modelings, the overall transition standard Gibbs free energy associated with the formation of the pentacoordinated intermediate from the reactants is $121 \mathrm{~kJ} \mathrm{~mol}^{-1}$ at $25^{\circ} \mathrm{C}(\mathrm{SMD} / /$ M06-2X/6-31++G**) and the transition standard Gibbs free energy associated with the highest transition structure along the less energetic route that allows the racemization of the pentacoordinated intermediate through Berry pseudo rotations is, with the same energetic reference, $124 \mathrm{~kJ} \mathrm{~mol}^{-1}$ at $25^{\circ} \mathrm{C}$ (SMD//M06-2X/6-31++G**). Pseudo rotations of the pentacoordinated intermediate are consequently competitive with the elimination of an alcohol molecule.

The racemization kinetics of ethyl hydrogeno-phenylphosphinate in pure ethanol at $78{ }^{\circ} \mathrm{C}$ has experimentally been monitored using chiral HPLC. The formal kinetic model predicted from DFT calculations has then been found to fit pretty well with these experimental data and experimental transition standard Gibbs free energies have been extracted with a good precision $\left( \pm 0.3 \mathrm{~kJ} \mathrm{~mol}^{-1}\right)$. These energies unexpectedly exhibit a weak, but real, dependency on the phosphinate concentration, which is characterized by the following equation (unit: $\mathrm{kJ} \mathrm{mol}^{-1}$ ): 133.4-0.65 $\log _{10}\left(\mathrm{c}_{\mathrm{p}} / \mathrm{c}^{\mathrm{o}}\right.$ ). This slight dependency has been interpreted as a possible acidobasic catalytic action of a second phosphinate molecule in the alcohol exchange reaction, but this still needs to be proven.

Except this question that remains open, experimental and predicted transition standard Gibbs free energies have here been proven to be compatible and this makes us rather confident in the fact that the proposed mechanism is realistic.

\section{Synthesis methodology}

In a dry $250 \mathrm{~mL}$ bicol round flask under argon, $80 \mathrm{~mL}$ of THF are introduced and cooled at $0{ }^{\circ} \mathrm{C} .9 .2 \mathrm{~g}$ of dichlorophenylphosphine $(51.4 \mathrm{mmol})$ are diluted, then $32 \mathrm{~mL}$ 
of ethanol are added dropwise. The agitation is maintained during $20 \mathrm{~h}$ at room temperature. The solution is then concentrated under reduced pressure and under vacuum. The ethyl hydrogeno-phenylphosphinate is obtained with a $95.3 \%$ yield (8.3 g).

\section{NMR analysis}

$\mathrm{NMR}{ }^{1} \mathrm{H}\left(\mathrm{CDCl}_{3}, 400 \mathrm{MHz}\right): \delta 1.10\left(\mathrm{t},{ }^{4} \mathrm{~J}=6.6 \mathrm{~Hz}, 3 \mathrm{H}\right), 3.88$ $(\mathrm{m}, 2 \mathrm{H}), 7.32\left(\mathrm{~d},{ }^{1} \mathrm{~J}_{\mathrm{P}-\mathrm{H}}=563.88 \mathrm{~Hz}, 1 \mathrm{H}\right), 7.24-7.55(\mathrm{~m}$, $\left.5 \mathrm{H}_{\text {arom }}\right) . \mathrm{RMN}^{31} \mathrm{P}\left\{{ }^{1} \mathrm{H}\right\}\left(\mathrm{CDCl}_{3}, 400 \mathrm{MHz}\right): \delta 25.0$ (s).

\section{Chiral HPLC}

Enantio-enriched ethyl hydrogeno-phenylphosphinate was refluxed in $30 \mathrm{~mL}$ of ethanol. Aliquots of this solution were injected on Lux-Cellulose-2 $(250 \times 4.6 \mathrm{~mm}$, Cellulose tris (3-chloro-4-methylphenylcarbamate), heptane/ethanol 80/20, $1 \mathrm{~mL} / \mathrm{min}$, UV detection at $220 \mathrm{~nm}$, Retention times: 8.2 and $10.8 \mathrm{~min}$ ) to monitor the enantiomeric excess over time.

Acknowledgments Guilhem Javierre thanks the Ecole Centrale de Marseille (http://www.centrale-marseille.fr) and the Provence-AlpesCôte-d'Azur Region (http://www.regionpaca.fr), as well as the Centre Régional d'Innovation et de Transfert de Technologie Chimie \& Matériaux Novachim (http://www.novachim.fr) for their financial support. All authors thank the Centre Régional de Compétences en Modélisation Moléculaire for computational resources (http://fr-chimie. univ-amu.fr/crcmm).

\section{References}

1. Anastas PT, Warner JC (2000) Green chemistry: theory and practice. Oxford University Press

2. Noyori R, Ikeda T, Ohkuma T, Widhalm M, Kitamura M, Takaya H, Akutagawa S, Sayo N, Saito T (1989) Stereoselective hydrogenation via dynamic kinetic resolution. J Am Chem Soc 111:9134 9135. doi:10.1021/ja00207a038

3. Mashima K, Matsumura Y, Kusano K, Kumobayashi H, Sayo N, Hori Y, Ishizaki T, Akutagawa S, Takaya H (1991) Highly stereoselective asymmetric hydrogenation of 2-benzamidomethyl3-oxobutanoate catalysed by cationic binap-ruthenium(II) complexes. J Chem Soc Chem Commun doi:10.1039/C39910000609

4. Kumobayashi H (2010) Erratum to "industrial application of asymmetric reactions catalyzed by BINAP-metal" [Recl. Trav. Chim. Pays-bas 115 201-210 (1996)]. Recueil des Travaux Chimiques des Pays-Bas 115:381-381. doi:10.1002/recl.19961150709

5. Dobbs DA, Vanhessche KPM, Brazi E, Rautenstrauch V, Lenoir JY, Genêt J-P, Wiles J, Bergens SH (2000) Industrial synthesis of (+)-cis-methyl Dihydrojasmonate by Enantioselective catalytic hydrogenation; identification of the precatalyst $[\mathrm{Ru}((-)$-me-DuPHOS $)$ (H)( $16-1,3,5$-cyclooctatriene)](BF4). Angew Chem Int Ed 39: 1992-1995. doi:10.1002/1521-3773(20000602)39:11<1992::AIDanie1992>3.0.CO;2-W
6. Togni A (1996) Planar-chiral ferrocenes: synthetic methods and applications. Angew Chem Int Ed Engl 35:1475-1477. doi:10. 1002/anie.199614751

7. Knowles WS (2002) Asymmetric hydrogenations (Nobel lecture) copyright $\odot$ the Nobel foundation 2002. We thank the Nobel foundation, Stockholm, for permission to print this lecture. Angew Chem Int Ed 41:1998. doi:10.1002/1521-3773(20020617)41: 12<1998::AID-ANIE1998>3.0.CO;2-8

8. Blaser H-U, Federsel H-J (2010) Asymmetric catalysis on industrial scale: challenges, approaches and solutions, 2nd edn. Wiley-VCH, Weinheim

9. Tang W, Zhang X (2003) New chiral phosphorus ligands for Enantioselective hydrogenation. Chem Rev 103:3029-3070. doi: $10.1021 / \mathrm{cr} 020049 \mathrm{i}$

10. Börner A (2008) Phosphorus ligands in asymmetric catalysis. Wiley-VCH, Weinheim

11. Noyori R (2013) Facts are the enemy of truth-reflections on serendipitous discovery and unforeseen developments in asymmetric catalysis. Angew Chem Int Ed 52:79-92. doi:10.1002/anie. 201205537

12. Herault D, Buono G, Vanthuyne N, Roussel C, Giordano L, Moraleda D, GATINEAU D, Leclaire J, Nuel D (2014) WO Patent WO/2014/108487: P-stereogenic chiral precursor of chiral ligands and use thereof. https://patentscope.wipo.int/search/en/ WO2014108487.

13. Ackermann L (2006) Air- and moisture-stable secondary phosphine oxides as Preligands in catalysis. Synthesis 2006:1557-1571. doi: $10.1055 / \mathrm{s}-2006-926427$

14. Erre G, Enthaler S, Junge K, Gladiali S, Beller M (2008) Synthesis and application of chiral monodentate phosphines in asymmetric hydrogenation. Coord Chem Rev 252:471-491. doi:10.1016/j.ccr. 2007.09.021

15. Montchamp J-L (2014) Phosphinate chemistry in the 21st century: a viable alternative to the use of phosphorus Trichloride in organophosphorus synthesis. Acc Chem Res 47:77-87. doi:10.1021/ ar400071v

16. Leyris A, Bigeault J, Nuel D, Giordano L, Buono G (2007) Enantioselective synthesis of secondary phosphine oxides from (RP)-(-)-menthyl hydrogenophenylphosphinate. Tetrahedron Lett 48:5247-5250. doi:10.1016/j.tetlet.2007.05.140

17. Gatineau D, Nguyen DH, Hérault D, Vanthuyne N, Leclaire J, Giordano L, Buono G (2015) H-Adamantylphosphinates as universal precursors of P-Stereogenic compounds. J Org Chem 80:41324141 doi: $10.1021 /$ acs.joc. 5 b00548

18. van Bochove MA, Swart M, Bickelhaupt FM (2009) Stepwise walden inversion in nucleophilic substitution at phosphorus. Phys Chem Chem Phys 11:259-267. doi:10.1039/B813152J

19. van Bochove MA, Swart M, Bickelhaupt FM (2006) Nucleophilic substitution at phosphorus $\left(\mathrm{S}_{\mathrm{N}} 2 @ \mathrm{P}\right)$ : disappearance and reappearance of reaction barriers. J Am Chem Soc 128:10738-10744. doi: $10.1021 / \mathrm{ja} 0606529$

20. Hammond PR (1962) 258. Ionisation of the P-H bond. Deuteriumexchange studies with diethyl and ethyl hydrogen phosphonate. J Chem Soc pp 1365-1369. doi:10.1039/JR9620001365

21. Wang F, Polavarapu PL, Drabowicz J, Mikołajczyk M (2000) Absolute configurations, predominant conformations and tautomeric structures of enantiomeric tert-butylphenylphosphine oxides. J Org Chem 65:7561-7565. doi:10.1021/jo000923c

22. Mamaev VM, Prisyajnuk AV, Laikov DN, Logutenko LS, Babin YV (1999) The mechanism of a diad prototropic rearrangement of hydrophosphorylic compounds. Mendeleev Communications 9: 240-241. doi:10.1070/MC1999v009n06ABEH001095

23. Babin YV, Prisyazhnyuk AV, Ustynyuk YA (2008) A density functional theory study of dimers of hydrophosphoryl compounds and proton transfer in them. Russ J Phys Chem A 82:94-100. doi:10. $1134 / \mathrm{S} 0036024408010147$ 
24. Janesko BG, Fisher HC, Bridle MJ, Montchamp J-L (2015) P(=O) $\mathrm{H}$ to $\mathrm{P}-\mathrm{OH}$ Tautomerism: a theoretical and experimental study. J Org Chem 80:10025-10032. doi:10.1021/acs.joc.5b01618

25. Stewart JJP (2007) Optimization of parameters for semiempirical methods V: modification of NDDO approximations and application to 70 elements. J Mol Model 13:1173-1213. doi:10.1007/s00894007-0233-4

26. Frisch MJ, Trucks GW, Schlegel HB, Scuseria GE, Robb MA, Cheeseman JR, Scalmani G, Barone V, Mennucci B, Petersson GA, Nakatsuji H, Caricato M, Li X, Hratchian HP, Izmaylov AF, Bloino J, Zheng G, Sonnenberg JL, Hada M, Ehara M, Toyota K, Fukuda R, Hasegawa J, Ishida M, Nakajima T, Honda Y, Kitao O, Nakai H, Vreven T, Montgomery Jr JA, Peralta JE, Ogliaro F, Bearpark M, Heyd JJ, Brothers E, Kudin KN, Staroverov VN, Kobayashi R, Normand J, Raghavachari K, Rendell A, Burant JC, Iyengar SS, Tomasi J, Cossi M, Rega N, Millam JM, Klene M, Knox JE, Cross JB, Bakken V, Adamo C, Jaramillo J, Gomperts R, Stratmann RE, Yazyev O, Austin AJ, Cammi R, Pomelli C, Ochterski JW, Martin RL, Morokuma K, Zakrzewski VG, Voth GA, Salvador P, Dannenberg JJ, Dapprich S, Daniels AD, Farkas Ö, Foresman JB, Ortiz JV, Cioslowski J, Fox DJ (2009) Gaussian 09, revision D.01. Gaussian Inc., Wallingford

27. Zhao Y, Truhlar DG (2008) The M06 suite of density functionals for main group thermochemistry, thermochemical kinetics, noncovalent interactions, excited states, and transition elements: two new functionals and systematic testing of four M06-class functionals and 12 other functionals. Theor Chem Accounts 120:215241. doi:10.1007/s00214-007-0310-x

28. Marenich AV, Cramer CJ, Truhlar DG (2009) Universal solvation model based on solute electron density and on a continuum model of the solvent defined by the bulk dielectric constant and atomic surface tensions. J Phys Chem B 113:6378-6396. doi:10.1021/ jp810292n

29. Barone V, Cossi M (1998) Quantum calculation of molecular energies and energy gradients in solution by a conductor solvent model. J Phys Chem A 102:1995-2001. doi:10.1021/jp9716997

30. Cossi M, Rega N, Scalmani G, Barone V (2003) Energies, structures, and electronic properties of molecules in solution with the C-
PCM solvation model. J Comput Chem 24:669-681. doi:10.1002/ jcc. 10189

31. Lide DR, Frederikse HPR (1997) CRC handbook of chemistry and physics, 78th edn. CRC, Boca Raton

32. Olmstead WN, Margolin Z, Bordwell FG (1980) Acidities of water and simple alcohols in dimethyl sulfoxide solution. J Org Chem 45: 3295-3299. doi:10.1021/jo01304a032

33. Kolthoff IM, Chantooni MK, Bhowmik S (1968) Dissociation constants of uncharged and monovalent cation acids in dimethyl sulfoxide. J Am Chem Soc 90:23-28. doi:10.1021/ja01003a005

34. Crampton MR, Robotham IA (1997) Acidities of some substituted ammonium ions in dimethyl sulfoxide. J Chem Rese 22-23. doi:10. 1039/a606020j

35. Bordwell FG, Algrim D (1976) Nitrogen acids. 1. Carboxamides and sulfonamides. J Org Chem 41:2507-2508. doi:10.1021/ jo00876a042

36. Chmurzynski L, Warnke Z (1993) Acid-Base equilibria of substituted pyridine $\mathrm{N}$-oxides in $\mathrm{N}, \mathrm{N}$-dimethylformamide and dimethyl sulfoxide. Aust J Chem 46:185. doi:10.1071/CH9930185

37. Bordwell FG (1988) Equilibrium acidities in dimethyl sulfoxide solution. Acc Chem Res 21:456-463. doi:10.1021/ar00156a004

38. Benoit RL, Lefebvre D, Fréchette M (1987) Basicity of 1,8-bis (dimethylamino)naphthalene and 1,4-diazabicyclo[2.2.2]octane in water and dimethylsulfoxide. Can J Chem 65:996-1001. doi:10. $1139 / \mathrm{v} 87-170$

39. Berry RS (1960) Correlation of rates of intramolecular tunneling processes, with application to some group V compounds. J Chem Phys 32:933. doi:10.1063/1.1730820

40. Muetterties EL, Mahler W, Packer KJ, Schmutzler R (1964) Fivecoordinate stereochemistry. Inorg Chem 3:1298-1303. doi:10. 1021/ic50019a022

41. Wang P, Zhang Y, Glaser R, Reed AE, Schleyer PAVR, Streitwieser A (1991) The effects of the first- and second-row substituents on the structures and energies of PH4X phosphoranes. An ab initio study. J Am Chem Soc 113:55-64. doi:10.1021/ja00001a011

42. Noorizadeh S (2005) The maximum hardness and minimum polarizability principles in accordance with the bent rule. J Mol Struct THEOCHEM 713:27-32. doi:10.1016/j.theochem.2004.09.029 